\title{
DEL TEXTO AL ESPEJO. LA BÚSQUEDA Y PÉRDIDA DE LA IDEA DE ANTROPOLOGÍA SOCIAL
}

\section{OF THE TEXT TO THE MIRROR. SEARCH AND LOSS OF THE IDEA OF SOCIAL ANTHROPOLOGY}

\author{
José-Luis Anta Félez \\ Universidad de Jaén
}

\begin{abstract}
Resumen.- Desde los años 80 del anterior siglo la antropología se había planteado que lo que estudiaba era en cierta medida una serie de textos, la cultura, el Otro, eran en este sentido un texto que había que desentrañar, leer e interpretar. La credencial de la antropología no era otra que la de ser una teoría de la lectura especializada en un mundo de diversidades. O, acaso, un viajero experto. El advenimiento y caída de una mirada postmoderna proponía que esta forma de ver las cosas recreaba una crítica propia de la antropología que tenía algo de suicida y autodestructivo. La propuesta, consecuentemente, es localizar otras metáforas, de ahí el espejo, una forma tan evocativa e intermedia de encontrar el punto de encuentro entre los intereses de la antropología, el trabajo de campo y el propio self-antropológico.
\end{abstract}

Palabras clave.- antropología social; texto; espejo; auto-etnografía; pensamiento crítico

\begin{abstract}
Since the 80 s of the previous century Anthropology had arisen what studying was to some extent a series of texts, the culture, the other, were here a text to unravel, read and interpret. The credential of anthropology was none other than be a theory of reading specialized in a world of diversity, or, perhaps, an expert traveler. The advent and fall of a post-modern look proposed that this way of seeing things recreated a critique of anthropology which had some suicidal and self-destructive. Proposal, as a result, is to locate other metaphors, hence the mirror, a very evocative and intermediate form of finding the point of contact between the interests of anthropology, fieldwork, and his own self-anthropological.
\end{abstract}

Keywords.- social anthropology; text; mirror; auto-ethnography; critical thinking

"Uno de los textos de Leiris "L'oeil de l'ethnographe", vuelto a publicar en Zébrage, da cuenta de su visión de África antes de emprender viaje con Griaule. Visión colonial, visión infantil, visión de niño colonial, como el propio Leiris insiste en mostrar".

Entre Tintín y Tartarín. Fernando Giobellina

"Los héroes clásicos reflejados en los espejos cóncavos dan el Esperpento. El sentido trágico de la vida española sólo puede darse con una estética sistemáticamente deformada".

Luces de bohemia. Valle-Inclán.

I.

Homi Bhabha ha propuesto el concepto postcolonial en un sentido nuevo y distintivo: se trata de una condición histórica para explicar las variaciones y diferencias de la modernidad en diferentes contextos de tipo nacional (Bhabha, 2000). Para ello, además, hace una apuesta nueva por la lectura de los 
discursos en condiciones de carácter literario y textual (Bhabha, 1990: 291-322. Fernández de Rota, 2000: 223-230). Tenemos, consecuentemente, dos puntos de arranque que hacen de todo ello una teoría altamente fortificada: por un lado, la idea de nación, supuestamente entendida en sus niveles de tradiciónmodernidad (pasando por la identidad/etnicidad), y, por otro, la idea de texto, establecida, a su vez, en el juego de representación-recreación (que pasa por la idea de traducción-literalización). No estamos hablando de algo desconocido en el mundo de la antropología; de hecho, los grandes estructuralistas como Lévi-Strauuss o los simbolistas como Clifford Geertz habían establecido en torno al texto, de alguna manera, el centro de su pensamiento, aunque quizás no con la fuerza que desde la idea postcolonial se plantea en torno a la idea de nación. Pero la idea básica de que existe una relación directa entre el texto y la idea nación sí que tiene algo que suena de otra manera. Obviamente que la raíz de todo ello es la mirada postestructuralista que la anima:

"La gran virtud de la extensión de la noción de texto más allá de las cosas escritas en papel o esculpidas en piedra es que dirige la atención sobre precisamente este fenómeno: cómo se lleva a cabo la inscripción de la acción, cuáles son sus vehículos y cómo trabajan, y qué es lo que la fijación del significado a partir del flujo de sucesos (la historia a partir de lo que sucedió, el pensamiento a partir de lo pensado, la cultura a partir de la conducta) implica para la interpretación sociológica. Contemplar las instituciones sociales, las costumbres sociales, los cambios sociales como "legibles" en algún sentido, implica modificar todo nuestro sentido sobre lo que es la interpretación hacia modos de pensamiento más familiares al traductor, al exégeta o al iconógrafo que al administrador de tests, al analista factorial o al empadronador" (Geertz, 1980: 45).

Es seguro que como nos propusieron desde el Seminario de Santa Fe (Clifford; Marcus, 1991) la importancia del texto es fundamental para comprender si no toda por lo menos sí gran parte de la idea de antropología. En última instancia, nos recuerdan que la antropología es alegoría, retórica y textualidad. Por ello mismo me interesa ahora desentrañar las formas en cómo se aborda el texto antropológico. Porque evidentemente la lógica que establece cómo se pasa de las notas de campo (field-notes) al texto antropológico tiene que estar cargada de elementos sustanciales y discursividades que hacen que se pase de la experiencia a la experimentalidad. Para ello hay básicamente dos conceptos que son claves: el de realidad y el de verdad, ambos en la medida que pueden ejercitarse en su sentido negativo, el texto etnográfico no tiene por qué estar conectado ni con lo real, ni dar apariencia de verdad. Sin embargo siítiene que ser verosímil y realista. De hecho es la concentración sobre las notas de campo lo que lo aleja de lo que es, el texto etnográfico al ser la versión definitiva de una escritura es una representación de una traducción. Es la retórica cultural del ejercicio poético social. Y, consecuentemente, ¿dónde está el anclaje entre lo real y lo realista, entre la verdad y lo verosímil? Es más, ¿puede existir una etnología sin etnografía?, quizás sólo en la idea de viaje (Clifford, 1999). ¿Son los textos etnográficos tenaces libros (disciplinares y científicos) de viajes? Sin duda, de ahí la antropología de Mauss, Leiris, Griol, Lévi-Strauss, Turner y Geertz donde se pauta el viaje irrepetible de lo real (experiencial) a lo verosímil (experimental). 
Al concentrar en el texto la idea de viaje la antropología da un giro hacia todo un cúmulo de tradiciones que abarcan la literatura (como ensoñación del viaje interior) y, como no, al propio viaje en cuanto desplazamiento. El texto es un recorrido en manos del escritor, y el lector sólo puede, como en la novela francesa del siglo XIX (Dumas, por ejemplo), establecer un criterio de ensoñación. De creación de la imaginación a la imaginación del lector. La antropología como viaje y las etnografías como formas particulares de libro de viaje son una reiteración desde los años 80 . Porque más allá de lo que podían entender los antropólogos del núcleo duro de la postmodernidad, la conexión con el viaje tiene algo de recreado, pero también de desesperada supervivencia. Plantear los textos etnográficos como una suerte de libro de viaje tiene la ventaja de que pone a la antropología en una tradición muy particular, la de los viajeros, pero también en la de los momentos míticos en que el mundo, tan grande como se quisiera, tenía que ser descubierto, viajando y experimentado. Sumándose a esta tradición, con la perspectiva de no menos de un siglo, la antropología se pensaba como una disciplina de largo recorrido, que hacía del mundo algo más habitable, más conocido y menos ignorante. La cuestión que se planteaba, proponer los textos como un viaje experimental, tenía varias desventajas, la primera era de orden epistemológico, había que salvar la idea de diversidad desde un relativismo extremo, las otras eran de orden práctico, había que rivalizar con muchas otras modalidades de viaje (desde las propuestas por el turismo de masas a los organismos de ayuda a los países del tercer mundo), no había un mundo al que viajar para enseñar que no fuera previamente experimentado, cuando no transformado desde ahí mismo y, por último, las antropologías nacionales proponían que no era necesario el traslado, que las realidades diversas también se encontraban en el entorno de la antropología.

El hecho de encontrar un punto de anclaje, con sus enormes defectos, en el viaje tenía además dos claras consecuencias. Por un lado, resolvía la idea de que había que hacer demostraciones, casi empíricas, de haber estado allí (Geertz, 1989). Y, por otro, resolvía la propia carrera del antropólogo como un viaje hacia algo, quizás parecido al conocimiento, pero también por los requisitos, no menos importantes, de las academias. El texto etnográfico como documento del viaje lo era también del autor. El autor aparece, se hace presente, en su carrera -pero esto es otro tema, que quizás tratemos más adelante-. Pero la cuestión, como ha puesto de relieve Clifford (1999: 29-64), es que existe una clara idea de que la distancia ya no es el factor clave del texto etnográfico. Muchos antropólogos "trabajan en casa" o al menos con temas y gentes que no necesariamente son parte de otros mundos o de lugares lejanos y exóticos. La movilidad, el gran metatema desde el siglo XX, es sin duda una voluntad. Una parte de un ejercicio mental donde el viaje se da no de manera física, lo que seguramente ya no tiene sentido en un mundo de rápidas conexiones y mínimas lagunas geográficas. El viaje es hacía el Otro. Lo que implica que no es necesario el desplazamiento. Solamente el viaje, que muchas veces es sólo interior. Las preocupaciones de los antropólogos nunca más que ahora han estado en entender su núcleo por comparación con el otro, todos los otros. Pero esto se ha resuelto de una manera, digamos, extraña, pues el otro era y es una construcción epistemológica. No existe un Otro en sí mismo, no existe el Otro extraño, sino un otro que vive en la idea conceptual de 
no estar dentro de los márgenes del nosotros, siempre un nosotros como antropólogos académicos.

Las dos grandes maneras de acercarse al otro, de construirlo como una realidad aparte $\mathrm{y}$, consecuentemente, como un elemento estudiable que ha sido exotizado y, lo que no es excluyente de lo anterior, tratarlo dentro de los temas emergentes de la antropología. Para que el otro fuera parte de una realidad no incluida en un criterio de subjetividad, y se pudiera tratar de manera científica, había que darle un barniz de diferenciación extrema por vía de sacar a luz aquellos elementos que por su apariencia les hacían más diferentes, más incompresibles, más lejanos. De nuevo la idea de que el antropólogo viajaba, se alejaba del centro era una de las claves. Pero no la única. Para exotizar hay que cargar la maleta de elementos propios, hay que acercarse a los otros en momentos clave donde los conceptos propios son fundamentalmente otros. Y esos momentos sí que han sido marcados claramente por la agenda de la antropología, sacando elementos emergentes a la realidad. Realidad que ha sido una suerte de laboratorio donde proponer los conceptos traídos desde la metrópoli. Porque esta antropología ha sido siempre conceptualmente viajera y colonialista, ahora postcolinialista, pero siempre determinando claves marcadas desde la centralidad académica. El otro importa en la medida que es operativo en el enorme entramado de la exotización.

II.

Antes de los años 70 del anterior siglo estaba vigente la idea del etnógrafo en soledad que encontraba su objeto de estudio después de buscarlo. Su trabajo de campo era un ritual de iniciación, en el cual la subjetividad era un elemento trascendente. Aunado a esa búsqueda, era condición sine qua non el distanciamiento a la hora de escribir y reflejar lo más fielmente la realidad, precisamente porque se reconocía y percibía una empatía con la cultura estudiada. La etnografía, por tanto, era considerada como un medio transparente para hacer aparecer, como por arte de magia, la cultura. Si la descripción era fría se consideraba como conocimiento científico. Otro de los tópicos consistía en dividir, a la manera estructural-funcionalista, el objeto en capítulos (parentesco, economía, etc.) puesto que la sociedad era un sistema donde todos los elementos remitían a esta totalidad (a este respecto Jociles, 1999 ha hecho un retrato muy acertado de las múltiples situaciones resituadas en la investigación en antropología).

Por tanto, aquello que se postulaba en la teoría y la etnografía era que la sociedad funcionaba como un todo coherente, desmenuzado en partes (ver Bestard, 1993, sobre la etnografía realista). En el método clásico del etnógrafo -la observación participante- estaba contenida una tensión crónica entre objetivación y subjetivación. Las reflexiones de los propios antropólogos sobre su trabajo de campo se solían plantear como una experiencia personal, habitualmente narradas en el capítulo introductorio de los textos. Servía también para reforzar ese "estar allí", marcando la presencia del etnógrafo. Se suponía que el etnógrafo poseía el autocontrol -como la cultura burguesa- y, en cambio, se suponía que el informante se expresaba a sí mismo. En realidad, en las situaciones de contacto domina más la incoherencia que la coherencia. 
Por tanto, los elementos que respondían a prácticas no sociales no eran analizables y eran eliminados de las etnografías. De este modo, la antropología resultaba ser una práctica muy objetivada porque los otros estaban muy objetivados. En cambio, los antropólogos no lo estaban por culpa de la práctica teórica de las ciencias sociales.

En suma, la condición para que la etnología fuera una ciencia objetiva debía ser borrar el trabajo de campo entendido como narración personal. El extranjero y el anfitrión se ubicarían en una situación de interlocución compleja; por lo tanto, ambos no podrían ser evocados más que en el texto -fuera de contexto- a través de otra obra que constituyera un género distinto: un diario íntimo como Malinowski o un relato filosófico como Tristes trópicos de LéviStrauss, los cuales no pretenden la cientificidad, ya que han elegido testimoniar esta interlocución, este elemento de intersubjetividad, a diferencia del texto científico que se consagra a los resultados de la descodificación. De todo ello, en consecuencia, se infería una dualidad mal conceptualizada. Una división tajante entre la experiencia de campo (la investigación) y los datos y teorías (los resultados, teóricos y descriptivos a la vez). En los Nuer o los Trobriandeses el etnógrafo desaparecía, sólo estaba en el prólogo. Por ejemplo, para Malinowski la sociedad era como un laboratorio. La observación equivalía a distancia y la participación a empatía. La experiencia se reducía a su diario personal, el cual tiene muchas virtudes, pero en el que no aparece una reflexión sobre la teoría del conocimiento antropológico, en oposición a la etnografía. Malinowski más que tomar parte en la vida del nativo metió su nariz $y$, en ocasiones, la pata. Su diario (y esa es una de sus virtudes) rompe con el mito del etnógrafo omnisciente y cosmopolita de la etnografía realista, la cual no era más que una convención cultural presentada frente a la cultura. Para Malinowski la participación era una técnica, un tipo de estrategia artificiosa para obtener información, la cual probablemente obtuvo del ambiente modernista polaco. Su idea era recoger los datos de forma cuidadosa, a la manera del naturalista. De forma similar, también era una estrategia de iniciación y conquista de un pueblo el método empleado por Marcel Griaule. Ambos iban a la caza de la presa, el nativo, el trofeo.

En los años 60 comienza a debatirse la idea de que en la cultura occidental cada vez más aparece una multiplicidad de intermediarios entre la experiencia inmediata del arte -una experiencia viva- y el público. Críticos, contracríticos, profesores universitarios y otros pensadores aparecen en la escena. Surgen metadiscursos, teorías sobre discursos de discursos. Desde las posiciones clásicas del modernismo se planteaba que este hecho apagaba el significado. Por ejemplo, a principios del siglo XX una de las formas de educación culta era la lectura de los clásicos, los cuales proporcionaban un sentido al presente. Hoy cada vez menos etnógrafos están convencidos de que exista una élite cultural, tal como se pensaba en el pasado. Dentro de la cultura humanística el punto de referencia para el conocimiento erudito eran los clásicos. Ahora no. Los clásicos sólo son objeto de conocimiento especializado. En suma, lo que ha entrado en crisis en el momento actual son las bases de la autoridad cultural y etnográfica. 
En los 70, la dicotomía experiencia entre el trabajo de campo y la etnografía comienza a resquebrajarse. Se rompe el orden de las etnografías y se cuestiona cómo se describe una cultura. Esta ya no se piensa como un modelo obligatorio de actuación, como si estuviera encima del individuo y le obligara a hacer lo que está programado. Por ejemplo, ya no se conceptúa el ritual como el momento en el cual se renuevan las relaciones sociales y se crea la solidaridad y la cohesión social, sino que también éstas se crean (toda la teoría de la práctica de Bourdieu), incluso empieza a percibirse al ritual como un momento en el cual el orden social ya no se refuerza, sino que se cuestiona. La idea geertziana de la cultura como programa que se opone al caos, a la ausencia de cultura (como si la cultura impusiera un orden), se revisa dado que, en realidad, en la cultura aparecen sujetos activos que se enfrentan. Ya no es posible pensar la cultura como un todo objetivable.

En definitiva, cada vez más se asume que los hechos se construyen y la etnografía se construye, rompiendo así con el empirismo naif. Por tanto, las observaciones no son puras puesto que dependen de la teoría. Al menos como ideal, etnógrafos e informantes crecientemente se transmutan en colaboradores en el trabajo e interpretación; no son sujeto y objeto (la reflexividad típicamente posmoderna). Ya en la década de los 70, las descripciones sobre una cultura toman la forma de etnografías polifónicas, a lo Bajtin, mostrando que no existe una representación etnográfica como sí aparecía en las etnografías clásicas. Van Maanen (1988) apuntaba que el trabajo de campo es por encima de todo interpretativo y activo, en el cual traducción e interpretación se dan al mismo tiempo. El poder sagrado de la etnografía en estos años estaba perdiendo fuerza, precisamente porque ya no era el cristal transparente de la realidad. Se planteaban las etnografías como géneros, construcciones, donde la narrativa era en sí misma ya un conocimiento. Las verdades elevadas por un modelo invariante y externo cada vez más no podían aplicarse a las etnografías. Las verdades debían ser contestadas.

Para la etnografía clásica, la cultura era un todo coherente, objetivable y estático, esperando a ser descubierta; parecía que los sujetos de estudio conocían la cultura propia inconscientemente o simplemente no eran capaces de reflexionar y elaborar exégesis tan profundas como las del antropólogo, entre otras cosas porque se suponía que estaban demasiado contaminados por sus propios valores culturales de referencia. En cambio, para la etnografía posmoderna, la cultura es no-estática, contradictoria y procesual, lo cual permite perspectivas más amplias. En este sentido, un individuo puede tener una visión parcial y contextualizada de su propia cultura. La pregunta del etnógrafo obliga a su interlocutor a que también interprete, negociando los significados, y puede aportar diversas razones. Cuando uno habla acerca de sus propias acciones proporciona una explicación y es posible que la justifique porque esté bien (legalismo ético); muchas de las declaraciones de nuestros informantes son del tipo "esto es lo nuestro", "esto es lo bueno", "esto es nuestra tradición". O incluso responden porque sea de derecho (jurídico), de modo que, por ejemplo, muchos campesinos hablan como notarios al referirse a sus tierras. En última instancia, una de las aportaciones de la corriente posmoderna en antropología ha sido poner de relieve la máxima de que la 
práctica social es irreductible, es decir, sólo podemos realizar una aproximación.

Este cambio de perspectiva se ha reflejado en la práctica etnográfica. Se ha pasado de una concepción conductista, según la cual la cultura determina la conducta de los individuos, quienes a su vez son receptores pasivos en el proceso de transmisión y reproducción, a una interpretativa de la cultura en la cual son los individuos quienes la crean y la manipulan. Desde este punto de vista, la cultura sería así una especie de conversación y discurso (Rapport, 1997), a lo Kenneth Burke, aquello que permite que nos entendamos, más que un texto como señalaba Geertz. En definitiva, la idea sería que no habría un lugar privilegiado para situar la cultura, teniendo en cuenta la premisa de que la cultura se compone de aspectos -algunos no vistos-, más que de elementos organizativos de una totalidad. Es por ello que actualmente se insiste cada vez más en hacer una interpretación desde dentro de la cultura, reflejando el mismo proceso etnográfico sus propias bases.

En efecto, ya nadie cree que las etnografías representen la realidad fielmente. Las etnografías son escritas, mediatizadas por el lenguaje. En este sentido, la retórica empleada en los textos no es puro adorno sino una forma de conocer, de evocar una forma de realidad. Por tanto, hay que tener en cuenta no solo las teorías o a los métodos sino al mismo hecho de escribir, el medio por el cual se describe. El trabajo de campo es un proceso de creación liminal, puesto que se crea en la frontera de una cultura o situación cultural. El etnógrafo no entra en el centro de la cultura que estudia, sino que su presencia contribuye a crear un objeto híbrido, obligado a compartir símbolos. Cualquier interpretación supone ruptura, fragmentación de conocimientos, no una visión global. El etnógrafo se ha de conformar con "evocar" una totalidad.

III.

En este panorama confuso surge la cuestión -cada vez más asumida- en relación a que, probablemente, los discursos de los nativos no equivalen a la explicación de los hechos. Cada vez las sospechas son más fundadas respecto a que la verdad no está en ninguna parte (tampoco del lado del antropólogo) y resulta sumamente arriesgado elevar discursos con una cierta pretensión de verdad o para señalar algún tipo de sentido. De esta manera, la corriente posmoderna en antropología ubica al etnógrafo dentro del proceso de negociación de significados, en el cual crea su propio espacio. Rabinow (1992) deconstruye magistralmente la división sujeto/objeto (experiencia/datos) de la antropología clásica en su experiencia marroquí. Rabinow plantea novedosamente la experiencia de campo, su pecado exhibicionista, como una experiencia de conocimiento en sí misma. El etnógrafo ya no representaría ser una persona neutra, capaz de todo tipo de relación. Paralelamente, Rabinow muestra cómo el informante se comporta frente al antropólogo de una forma bastante diferente a como lo hace con los suyos.

Barley (2002) ya había apuntado algo similar en tono de humor respecto a que los informantes dowayos estaban más preocupados en mostrarle una buena fachada e impresión como buenos informantes que de proporcionarle 
información fidedigna. Lo que los posmodernos expresan es que el antropólogo y el informante se encuentran ubicados en un mundo mediatizado, insertos en una red que ellos han creado. En consecuencia, no existe una manera válida para eliminar la conciencia de ambos, no existe ninguna perspectiva absoluta. Por lo tanto, el trabajo de campo sería un proceso de creación liminal, puesto que se crea en la frontera de una cultura o situación cultural (Fabietti, 1999. Cardoso de Oliveira, 1998). El etnógrafo, por mucho que imagine, no entra en el centro de la cultura que estudia, sino que su presencia contribuye a crear un objeto híbrido, obligado a compartir símbolos. Cualquier interpretación supone ruptura, fragmentación de conocimientos. El etnógrafo no puede aspirar a una visión global, como por ejemplo saber perder el tiempo. El saber de una etnografía no es un saber total sino que está pasado por el tamiz de la ignorancia. Consecuentemente, un trabajo de campo en otro lugar no es un derecho, sino una confidencia. No se exige porque no hay derecho a exigir. Si existe un derecho de molestar es porque existe una relación de poder entre el antropólogo y el informante, que los antropólogos dialógicos sólo alcanzan a minimizar.

Los antropólogos hemos elegido un trabajo complicado y en ambientes -zonas de contacto e intercambios- complicados (Fabietti, 1999: 6). Llegar al campo y sentirse ridículo, experimentar malos entendidos y sin sentidos, es algo que forma parte de nuestra cotidianidad. Si la metodología del trabajo de campo debiera ser, idealmente, un recurso para plantear problemas antes que para solucionarlos, los problemas surgen inevitablemente: por la personalidad profesional propia, su problematización, lo movible de la identidad del antropólogo y de los otros, lo cual es, por otro lado, un asunto histórico; por la construcción del sujeto/objeto como relación recíproca y, sin duda, como relación de poder en el aspecto práctico (el rubro sería "el antropólogo que impone su poder"); y por la idea de que no existe una sola voz y que la cultura, en consecuencia, no es la suma de todas las partes, lo cual corre el riesgo de convertirse en un psicologismo, es más, en un solipsismo que reduce la multiplicidad al todo. Pensar, por otro lado, que el etnógrafo puede entrar al centro de una cultura es pensar que esa cultura es inferior, simple, es decir, más fácil de aprender que tu propia cultura que ha necesitado décadas de dedicación para comprenderla/aprehenderla. Una idea más prudente es quedarse, no ya en los límites, sino en esa frontera de la cual nos habla Fabietti, un espacio de contacto. Para el nativo, a su vez, el etnógrafo será un ignorante porque se le escaparán cosas; pero para conocer una cultura hay que aceptar que un conocimiento limitado puede ser suficiente. El etnográfo hoy reconoce crecientemente los límites de los aspectos que se conocen, puesto que es sabedor de que no se conoce una totalidad homogénea.

El Geertz (1989) de El antropólogo como autor retoma esta discusión acerca de la crisis a la hora de representar a otras culturas, influenciando directamente otro trabajo clave: La antropología como critica cultural de Marcus y Fischer (1991). Esta aproximación meta-textual -la idea de la antropología como texto de un texto que es la cultura-, enfatiza el hecho de que ya nadie cree que las etnografías representen la realidad fielmente. Las etnografías son escritas, mediatizadas por el lenguaje. En este sentido, la retórica empleada en los textos no es puro adorno sino una forma de conocer, de evocar una forma de 
realidad. Por tanto, hay que tener en cuenta no sólo las teorías o los métodos, sino el mismo hecho de escribir, el medio por el cual se describe. Geertz no afirma que la antropología equivale a una literatura sino que se acerca a ella, lo cual es muy distinto. Se pone de manifiesto la subjetividad del etnógrafo frente a la objetividad de la cultura, definida por la distancia. Es el "estar allí", el conseguir que el lector vea la otra cultura como la vio el etnógrafo, una experiencia de postal.

Algunos antropólogos han tendido a desmitificar el trabajo de campo como rito iniciático y preguntarse cómo se traslada una visión subjetiva a una representación objetiva. Clifford (1995) propone la cultura como un discurso, en el cual no existen elementos prefijados. Aparentemente Clifford rompe con la metáfora geertziana de la cultura como texto; ya no es el texto que fija los elementos, sino la cultura heterogénea frente a la cultura homogénea. Pero en realidad Clifford (1999: 71-119) retorna a la metáfora de la cultura como texto en su célebre ensayo sobre el trabajo de campo, propugnando una etnografía sin etnografía y equiparando a la antropología con la crítica literaria. La metáfora de la cultura como texto, asumida en masa por los antropólogos en las últimas décadas, presenta varios problemas: ¿los símbolos culturales son verdaderamente como los símbolos de un texto?, ¿se aprende una cultura leyéndola, al igual que un texto? En realidad es raro que se conozca personalmente al autor de un texto, mientras el etnógrafo conoce primero a los autores y después, con dificultad, su "texto". Todo ello nos permitiría pensar que dicha metáfora se encuentra agotada cuando se comienza a interpretarla demasiado al pie de la letra (Piasere, 2002: 108-109).

Además, la metáfora de la cultura como texto, o dicho de otro modo, la objetivación de la cultura -como texto-, también esconde las relaciones de conocimiento para realizar esta etnografía. No olvidemos que la etnografía se elabora entre un nativo -situado en el lugar del sujeto de estudio- y un sabio el etnógrafo-, el cual en repetidas veces se designa con un pronombre indefinido (uno, cualquiera, etc.). Por ello, el nativo se convierte en una monstruosidad conceptual y el etnógrafo en un ser que habla, pero desprovisto de nombre propio. Al Clifford de las Etnografías como textos se le recrimina que, después de tanta crítica sobre la etnografía y tanta constatación de los elementos de artificiosidad en el lenguaje, se haya perdido el sentido de las etnografías, aquello que querían decir. Una crítica bastante lúcida es la de Piasere (2002: 16) quien señala que en las etnografías posmodernas, a fuerza de estudiar sólo la retórica del texto, aparece un exceso de análisis en la forma en detrimento del contenido. Toma a Clifford como centro de sus críticas y menciona que en sus textos "no se habla de hombres, de sensaciones, de pasiones, de vidas vividas, sino de textos, de textos y de textos", además de que "no obstante su continuo reclamo de que los textos etnográficos deben ser polífónicos y no monofónicos, sus textos no lo son en absoluto, y vehiculan constantemente un único mensaje: ¡vean, yo tengo razón!". Para Piasere, Clifford se auto-construye un nuevo oficio explotando en su beneficio el concepto de etnografía, "el del crítico literario que se convierte en metaetnógrafo: hace de sirena y atrae a los etnógrafos que capitanea bajo su sperberiano poder contagioso". 
Igualmente, el hecho de explicitar tantos elementos intermediarios en la construcción de una etnografía provoca la pérdida de autenticidad de la etnografía, lo que a su vez ha generado una reacción compensatoria al intentar recuperar a través del análisis la experiencia etnográfica. Probablemente, $-\mathrm{y}$ esto sea acierto-, se ha sofisticado tanto el trabajo de campo que ha perdido autenticidad. Y las etnografías, los análisis de sus supuestos, se han realizado en términos de discurso y representación para concluir que no dicen nada. Tantas críticas, revisiones y discursos sobre Malinowski han provocado que los Trobiandeses casi hayan desaparecido. La crítica de Llobera (1990: 50-51) apunta a la contradictoria identidad de la antropología (rediriendose a Geertz, 1986, sobre la permanente crisis de identidad de la misma), y cuando se refiere a la etnología dialógica señala cómo la reflexividad se está convirtiendo en la razón de ser de la antropología de una forma obsesiva. Esta es una de las críticas más comunes al posmodernismo. Si se compara a los antropólogos clásicos, digamos "modernos", con una formación bastante amplia, con los "posmodernos", éstos carecerían de esa autoridad formativa a fuerza de ser "reflexivos", de insistir en la hermenéutica y la interpretación para acabar mirándose el ombligo: se limitarían a ver otras culturas, describir sus impresiones y el efecto que ocasionan en el yo, y manifestarlo en una suerte de "yoísmo" exacerbado, lo que los impugnadores del movimiento denominan simplemente "narcisismo".

\section{IV.}

Pero la realidad es que desde una posición puramente académica, dedicada al conocimiento, tal cual lo entiende Hannah Arendt (1994), y contrapuesta a una idea general de acción, es decir, con un criterio político, la cultura es un texto, En la medida que remite a la creación puramente estructurante del antropólogo. Digamos que las sociedades no viven su cultura como lo entiende un antropólogo, sea cual sea, sino que este traduce a unos interés ajenos a lo social lo que ha tomado de esta, el texto. La crítica a los postmodernos por parte de Pisasere en este sentido está llena de verdad: el texto es posterior. Pero no se trata de un criterio de descubrimiento y mucho menos de iluminación, sino de recreación de una cultura por otra. Otra que es siempre la nuestra. Porque al darle la vuelta al argumento postmoderno se llega a la idea, ya apuntada por Alberto Cardín (1994), de que la antropología como el estudio del Otro es un acertijo. Está implícito que el Otro es algo que tiene que ver con nosotros y no con la realidad de otras gentes. Es, si se quiere, un juego de espejos: nos miramos en un espejo y nos preguntamos quién ese otro. Como siempre contesta repitiendo lo que decimos, acaso distorsionado, a lo más ralentizado, sin reconocer el eco, es evidente que nos ponemos a mirar tras el espejo y ahí está, primero, otra gente y luego toda nuestra basura (igual que detrás de cualquier otro mueble o debajo de la alfombra). La metáfora del espejo es poderosa porque refleja muy bien cómo nos vemos, no sólo a un nivel cognitivo, sino también cómo contextualizamos lo que percibimos (el espejo es una imagen que la antropología usa de manera muy recurrente, aunque más como recurso evocativo que como concepto, véase, así, Bartra, 1998. Fernández, 2008. Sevilla; et allí, 2003). 
Si nos fijamos en la España de hace unos años podíamos encontraré diferentes tipos de espejos, unos eran privados y otros íntimos, los públicos estaban en bares y comercios y tenían otras connotaciones. De los diferentes tipos los había con connotaciones de género e, incluso, de estatus. Así tenemos que en una casa había uno en el dormitorio, el espejo del armario, gran espejo que generalmente estaba tras la puerta y servía para verse de cuerpo entero; cerca nos encontramos con el espejo de la coquetas, de carácter puramente femenino era un lugar para que las mujeres se peinaran y maquillaran; el del cuarto de baño, que con el paso del tiempo se fue sofisticando, era el utilizado por los hombres; el del salón, generalmente asociado a un determinado estatus social y, por último, el de la entrada de la casa, un espejo que estaba entre lo público y lo privado y añadía no sólo profundidad a unas casas de largos y angostos pasillos sino, que dejaba impresa la imagen que se quería dar al salir de casa. Estos espejos reflejan de una manera u otra unos mundos, situaciones y formas de vivir lo social de manera diferente, y aún cuando todos están en una casa todos son diferentes y tienen una utilidad, un simbolismo y una ritualidad diferente. Era común, por ejemplo en la Galicia de hace unos años, tapar los espejos cuando moría alguien en la casa (Fernández de Rota, 1987), pero, al igual que se paraban los relojes, sólo se hacía con los que estaban más visibles, y aquellos que pertenecían al ámbito de lo intimo, como el del armario ropero o el del cuarto de baño, se dejaban tal cual. No es el momento de comentar todo esto sino de observar lo poderosa que es la metáfora del espejo y que tan generosamente plantea ciertas dudas de carácter epistemológico a la antropología.

Es evidente que si la antropología social es el espejo de la humanidad, como subtitula Kotak (2003) a su manual, tenemos que determinar a qué espejo nos referimos y cómo obviamos la enorme carga de narcisismo que esto conlleva. Porque la antropología no es sólo una ciencia del conocimiento, no es, incluso, una ciencia para el conocimiento, que también, es sobre todo una ciencia occidental de carácter narcisista. Lo es todo en occidente, pero la antropología al proponer a los otros como espejo multiplica su efecto visual $y$, consiguientemente, la manera en que explota su self. De aquí se pueden sacar ciertas conclusiones que podrían resumirse en una sola: la antropología social es una ciencia normalizada que no representa ningún peligro para occidente, por el contrario, es una suerte de recreación permanente del enorme poder de occidente. Incluso de la parte más blanda de ese poder: el de la academia, el del saber. Todo esto lo podemos entender desde la noción de conocimiento situado, es decir, desde un punto donde la comprensión de un hecho sólo puede partir de la posición en la que nos encontramos, rechazando el truco del ojo divino que realiza la etnografía realista (Haraway, 1995). En cuanto que el conocimiento depende de la perspectiva del observador, es necesaria una crítica ética y reflexiva de esa posición totalitaria e inequívoca. De hecho, podría parecer contradictorio que al dar la vuelta del espejo en el que se mira al otro produzca una invisivilización del investigador como lugar central de esa mirada. El reflejo en el espejo es el resultado de la mirada del espejo, no de la posición de la persona que mira. Así, pues, si el concomimiento es inmanente a nuestra posición, lo relevante de la investigación etnográfica no se localiza en la otredad del objeto de estudio, sino más bien en la otredad que emerge desde la posición de la persona que investiga. El investigador puede situarse en 
múltiples múltiples niveles como sujeto y objeto a la vez, sin que se le pueda asignar un único rol, identidad o práctica (Gutiérrez; Pujol, 2007). Incluso más allá de todo esto Bartolomé (2003) nos propone, al estilo de Alicia a Través del Espejo, trascender las fronteras refractivas del espejo y penetrar en el mundo que éste contiene. Pero fuera como fuese la idea de espejo tiene otra cara, el espejo no es fiel representación de la realidad, ni incluso de la occidental, es más bien un acuerdo de que podemos, queremos $\mathrm{y}$, en menor medida, debemos ver. $\mathrm{Y}$ así nos lo recuerda Michel Foucault:

"Creo que entre las utopías y estos sitios absolutamente otros, las heterotopías, podría haber una especie de experiencia mixta, conjunta, que sería el espejo. El espejo es, después de todo, una utopía, ya que es un lugar sin lugar. En el espejo, me veo allí donde no estoy, en un espacio irreal, virtual que se abre detrás de la superficie, estoy allí, allí donde no estoy, una especie de sombra que da mi propia visibilidad a mí mismo, que me permite verme allí donde estoy ausente: tal es la utopía del espejo. Pero también es una heterotopía en la medida en que el espejo no existe en la realidad, donde se ejerce una especie de neutralización de la posición que ocupo. Desde el punto de vista del espejo descubro mi ausencia en el lugar donde estoy ya que me veo allí. A partir de esta mirada que es, por así decirlo, dirigida hacia mí, desde el suelo de este espacio virtual que está al otro lado del cristal, me vuelvo hacia mí mismo, vuelvo a empezar a dirigir los ojos hacia mí y para reconstituir yo sé donde estoy. Las funciones del espejo como una heterotopía tienen este sentido: se hace de este lugar que ocupo en el momento en que me miro en el espejo a la vez absolutamente real, conectado con todo el espacio que lo rodea, y absolutamente irreal, ya que para que se perciba tiene que pasar por este punto virtual que está allá" (Foucault, 1984: 47. La traducción es mía).

Así, el espejo tiene esas dos cualidades, es un objeto fútil y a la vez la mediación de la utopía y lo heterotópico, por lo que recrea imágenes instantáneas que se desvanecen y sólo permanecen en la retina de aquel que tiene en frente. Por eso la principal herramienta de la antropología está en su capacidad de empatía, en el proceso del trabajo de campo: todo depende, todo es experimental, todo es instantáneo y único, todo está en la mano de un único individuo. $Y$ al no existir la posibilidad de la validación se tiene que confiar, autorizar y legitimar. El trabajo de campo juega en el borde del fracaso (de la utopía), pero no lo cruza porque utiliza la segunda propiedad de todo espejo (la heteropía): existe algo detrás y en torno a él. Como objeto físico tiene un delante y un detrás, un arriba y un abajo. El antropólogo, el buen antropólogo, es aquel que durante el trabajo de campo observa más allá del espejo que tiene delante. Es capaz de mirar más allá de la imagen que se refleja, traicionando el poder occidental y proponiéndose en el lugar de aquellos que no salen. Tampoco esto lo hace peligroso, pero si quizás sospechoso.

La historia de la antropología es la historia de un saber multi-paradigmático, de forma que un paradigma no es abandonado, como pensaba Kuhn, por ya no poder explicar la realidad, sino que el antropólogo no deja de estar influenciado contemporáneamente y más o menos conscientemente por otros paradigmas (Fabietti, 1999: 88). Es decir, parte del marxismo, del estructuralismo o del evolucionismo sigue hoy vigente en la teoría y la metodología antropológica. No 
es mi intención hacer un repaso exhaustivo de los paradigmas antropológicos a la manera de los manuales al uso sino reflexionar sobre los límites de la antropología en estos aspectos y plantear a continuación algunas ideas sobre la emergencia de la auto-etnografía como -iel último?- método del conocimiento antropológico. Los paradigmas son en sí mismos métodos antropológicos que permiten clasificar y etiquetar la realidad social y psicológicamente, al precio de empobrecer esa misma realidad que pretende describir e interpretar. Pero un método es más que una teoría puesto que ésta depende de más elementos. Toda metodología juega con el contexto de la realidad social, presentando además la creatividad y elementos condicionantes del investigador, de modo que se establece un compromiso entre la propia metodología, la realidad que estudia y el contexto del investigador.

Podemos apreciar mejor esto si imagináramos, hipotéticamente, la historia de la antropología dividida en dos grandes perspectivas en relación al método, la realidad y el contexto del investigador. La primera perspectiva, imaginemos, sería la del positivismo antropológico, cuyo mejor exponente es el estructuralfuncionalismo. Este enfoque plantearía el método científico como el salvador de la antropología, permitiendo la superación de los prejuicios personales y las mistificaciones que se hallen en la sociedad. A esta perspectiva la identificaríamos con el Método. La segunda perspectiva la identificaríamos con el posmodernismo antropológico. Aquí se presenta al individuo como salvador. El investigador es el protagonista de la reflexión antropológica, de forma que sería muy adecuada la sentencia del "antropólogo como héroe". Es aquí la Personalidad lo trascendente. Estas dos perspectivas coinciden, a grosso modo, con dos grandes sectores en la antropología: aquellos que creen que el método científico es suficiente y necesario para abordar objetivamente la realidad, y otros que piensan que el conocimiento antropológico es una cuestión de arte, de sensibilidad. Desde Marett, a inicios del siglo XX, hasta Firth se ha redundado en la idea de que la antropología simultáneamente es ciencia y literatura, resultando imposible eliminar del análisis los elementos de experiencia etnográfica, teoría y crítica cultural. En la antropología resulta imposible separar los elementos, aunque no debe olvidarse que en cuanto disciplina social tiene una parte de conocimiento científico: existen ciertos elementos que no pueden estudiarse simplemente por intuición.

Sin embargo, podríamos añadir una tercera perspectiva, más bien bizarra, o una síntesis imposible de las dos anteriores. En este caso sería la Cultura la que se erigiría contra la personalidad del antropólogo y contra el método. Esta idea no es nueva puesto que ya fue desarrollada por la antropología alemana de finales del XIX, siendo Leo Frobenius (1934) su creador. Este explorador y etnólogo concebía las diversas culturas como organismos cerrados, sujetos a las mismas leyes que regían a todos los seres vivos. Desde este punto de vista autopoiético, toda cultura poseería un alma propia, una singularidad y una individualidad que solo se encontraría en la naturaleza animada. Y así Frobenius consideraba a las distintas culturas como organismos vivos, sujetos a las leyes del mundo orgánico, que nacen, crecen -Ergriffenheit: participación emocional-, alcanzan su apogeo o madurez -Ausdruck: expresión-, envejecen y mueren -Andenbung: aplicación-. En consecuencia, atribuyó a cada cultura un conjunto de leyes que determinaba su desarrollo, independientemente de 
los individuos insertos en ella, dando forma a la teoría del paideuma, o alma de la cultura, una variación de la idea romántica de Volkgeist.

En esta perspectiva, tan humanista como arrogante, podríamos imaginar al antropólogo tan inmerso en los valores que está estudiando, intentando borrar su figura, que finalmente "haría de indígena", en una especie de Zelig, a lo Woody Allen, aquel personaje camaleónico capaz de mimetizarse con sus semejantes, apropiarse de sus valores y fundirse hasta adquirir su personalidad. En efecto, en este caso la Cultura sería omni-abarcadora y acabaría por absorber la propia personalidad del investigador. Y así una de las formas más recientes de romper con el positivismo antropológico es la autoetnografía. La autoetnografía representa una forma de auto-narrativa que sitúa el sí mismo en el interior de un contexto social determinado. Según ReedDanahay (1997) comprende diversas dimensiones: la antropología nativa producida por antropólogos nativos, quienes inicialmente eran estudiados por los antropólogos; la "autoetnografía étnica", escrita por miembros de grupos étnicos minoritarios; y la "etnografía autobiográfica", en la cual los antropólogos reflejan su experiencia personal en los textos.

Hay que destacar que el ejercicio del etnógrafo nativo es cada vez más común y de hecho representa una competitividad añadida al etnógrafo tradicional, quien ya no trabaja en exclusiva sobre sus sujetos de estudio (Lagunas, 2006). El riesgo, como señala Fabietti (1999: 55) en relación a lo que denomina el "nativismo etnográfico", es que la antropología nativa se convierta en una antropología "étnica", bajo la premisa errónea de que "el mejor conocedor de una cultura es el propio etnógrafo nativo" mientras al extranjero se le niega la facultad de representar a los otros. Es decir, se plantearía que para conocer e interpretar al otomí o al lacandón aquel que posee mayores competencias es el etnógrafo otomí o lacandón, lo cual raya con el racismo. Esta premisa se contesta sola: en realidad necesitamos todas las visiones, las de cualquier observador independientemente de su origen, con sus propios prejuicios, ya que el hecho es que los grupos y sus culturas no son elementos, ni objetos ni conceptos únicos. De hecho, al final ocurre que es cierto que la reducción de lo "propio" a un estereotipo vivible, tan fácil de manejar, experimentar y ficcionar, se hace corrosivo y falso.

Otro punto a tener en cuenta es que los antropólogos se cuestionan y se ven a sí mismos como parte de la experiencia de investigación, y que es algo común desde mediados de la década de los años 80 del siglo pasado, lo que significa una mirada propia a sus prácticas personales, ya sea en la introducción o integrado en el texto, como elemento irrenunciable. En efecto, como señala Cátedra (1992), la experiencia personal es ya conocimiento en sí. La autoetnografía es parte de un nuevo estilo etnográfico, la reflexividad, que incluye por igual los relatos breves, la poesía etnográfica o los textos performativos (Marzano, 2006. Sobre una mirada imprescindible de la posición ética, política, que esto supone véase Street, 2003). La crítica inmediata a la autoetnografía se centra en el enfoque sobre el yo, en el sentido de que su aportación no va más allá de una serie de reflexiones de un sujeto aislado, mientras los defensores plantean que esas reflexiones se vinculan con un contexto socio-cultural más amplio, además de la utilidad de explorar la propia 
subjetividad para comprender la subjetividad de los otros (así lo he trabajado en Anta, 2004). Auto-descubrimiento, auto-reflexión y comprensión de los otros se muestran como elementos indisolubles. Pero a diferencia del momento posmoderno, la actual auto-etnografía permite trabajar con lo empírico de una manera directa, conjurando el exceso de conceptos abstractos y aportando descripciones precisas. Una buena auto-etnografía no debe mostrar diferencias epistemológicas respecto a las demás etnografías, en última instancia todo es parte de un ejercicio de experimentación textual de esa suerte de reconocimiento del antropólogo -el self- en el espejo del Otro. En efecto, la mejor garantía de una buena auto-etnografía, y así de cualquier etnografía, es su reiteración como producto que se puede leer como un texto en el juego de creaciones parciales que dan los espejos en los que nos vemos reflejados.

Concluyendo, podemos decir que no hay que ser demasiado suspicaz para darse cuenta que la historia de las grandes artes, incluido el teatro y la literatura, que se ha hecho tiene una cierta obsesión por los espejos. En España podemos encontrar desde Velázquez, con las Meninas o su Venus ante el espejo, hasta la Colmena de Camilo José Cela, pasando por los espejos del callejón del Gato, que retratara Valle-Inclán en Luces de Bohemia, y así el espejo está siempre presente, no para mostrar un simple reflejo de la realidad, sino para valernos de su capacidad para distorsionarla. Una distorsión que recrea belleza o una fealdad absoluta. ¿Pero, acaso, no es exactamente esto lo que retratan los antropólogos al regresar de su trabajo de campo? Los antropólogos juegan con esta otra cualidad de los espejos: su capacidad para distorsionar la realidad, lo que es absolutamente fascinante. En este sentido no es ni la realidad, ni incluso el self-antropológico quienes parecen juegan un papel determinante por sí mismo, sino ese extraño punto medio que supone el juego de espejos, ese método que tiene la virtud de distorsionar la realidad (Godelier, 2002). Pero en antropología no hay sistema de control, no se puede establecer una cierta idea de cibernética de segundo grado, por lo que tiene que valerse de otros factores: la corrección del objeto reflejado en el gabinete $y$, sobre todo, en el contraste con los elementos interculturales, con la comparación -aunque un método nunca corrige a otro, sólo lo recrea-. Es ahí donde entra en juego la última de las características de los espejos: su capacidad para un desplazamiento, esa idea de que se puede jugar con ellos, de inventarlos fuera de sí, son las cajas de música, donde una imagen se multiplica hasta el infinito, y más porque lo que refleja es tan repetitivo como el baile en circular de una muñeca al ritmo de una música que dura lo que dure su cuerda. Es decir, la utopía del espejo: reflejar eternamente la misma cosa sin cambios, sin alteraciones, sin distorsiones. Acaso no es esto la utopía de la antropología, ¿la capacidad de fijar, con un método, la realidad primigenia y prístina más allá de todo estado mental, social e, incluso, cultural? Pero para ello tenemos que contar con esa extraña característica heterotópica que todo espejo tiene en las manos del sueño humano: su fragilidad como objeto, su posibilidad real de romperse, de hacerse mil pedazos, sin que ya tenga más utilidad que mostrarse como una suerte de tela de araña ficticia, que atrapa las imágenes en cada uno de sus trozos sin que, a su vez, tenga medio de recomponerse. 


\section{Agradecimientos}

Este trabajo parte de un proyecto con José Palacios (Univ. Católica San Antonio de Murcia) y David Lagunas (Univ. de Sevilla), donde intentamos la puesta en común de ciertas ideas y conceptos sobre nuestro mundo antropológico y que nunca materializamos.

\section{Bibliografía}

(2004) ANTA, José-Luis. "Búsquedas, miradas, sentidos: autoetnografía en la ciudad de México", en Cuicuilco, 11, 30: 1-19.

(1988) ARENDT, Hannah. Sobre la revolución. Madrid. Alianza.

(2002) BARLEY, Nigel. El antropólogo inocente. Notas desde una choza de barro. Barcelona: Anagrama.

(2003) BARTOLOMÉ, Miguel Alberto. "En defensa de la etnografía. El Papel contemporáneo de la investigación intercultural", en Revista de Antropología Social, 12: 199-222.

(1998) BARTRA, Roger. El salvaje en el espejo. México: ERA, UNAM.

(1993) BESTARD, Joan (Edit). Después de Malinowski. La Laguna: Dirección General de Patrimonio Histórico.

(2000) BHABHA, Homi K. The location of culture. Londres, Nueva York: Routledge.

(1994) BHABHA, Homi K. (Edit.). Nation and narration. Londres, Nueva York: Routledge.

(1998) CARDOSO DE OLIVEIRA, Roberto. O trabalho do antropólogo. São Paulo: Paralelo 15, UEP.

(1992) CÁTEDRA, María. "Prólogo a la edición española", en RABINOW, Paul. Reflexiones sobre un trabajo de campo en Marruecos. Madrid: Júcar.

(1991) BOURDIEU, Pierre. El sentido práctico. Madrid: Taurus.

(1994) CARDíN, Alberto. Dialéctica y canibalismo. Barcelona: Anagrama.

(1995) CLIFFORD, James. Dilemas de la cultura. Antropología, literatura y arte en la perspectiva posmoderna. Barcelona: Gedisa.

(1999) CLIFFORD, James. Itinerarios transculturales. Barcelona: Gedisa.

(1991) CLIFFORD, James; MARCUS, George E. (Edits.). Retóricas de la antropología. Madrid, Gijón: Júcar.

(1999) FABIETTI, Ugo. Antropología culturale. L'esperienza e l'interpretazione. Bari: Laterza.

(2000) FERNÁNDEZ BRAVO, Álvaro (Comp.). La invención de la nación: lecturas de la identidad de Herder a Homi Bhabha. Buenos Aires: Manantial.

(2008) FERNÁNDEZ JUÁREZ, Gerardo (Direct.). La diversidad frente al espejo: salud, interculturalidad y contexto migratorio. Quito: Abya-Yala.

(1987) FERNÁNDEZ DE ROTA, José Antonio. Gallegos ante un espejo. Imaginación antropológica en la historia. La Coruña: Do Castro.

(1984) FOUCAULT, Michel. "Des espaces autres", en Architecture, Mouvement, Continuité, 5: 46-49. (Conferencia dictada en el Cercle des études architecturals, 14 de marzo de 1967).

(1934) FROBENIUS, Leo. La Cultura como ser viviente. Contornos de una doctrina cultural y psicológica. Madrid: Espasa-Calpe.

(1986) GEERTZ, Cliford. "El reconocimiento de la antropología", en Cuadernos del Norte, 35: 59-63. 
(1989) GEERTZ, Cliford. El antropólogo como autor. Barcelona: Paidós.

(1994) GEERTZ, Cliford. Conocimiento local. Barcelona: Paidós.

(2002) GODELIER, Maurice. "Briser le miroir du soi", en GHASARIAN, Christian (Comp.). De L'ethnographie à l'anthropologie réflexive: 193-212. París: Armand Colin.

(2007) GUTIÉRREZ MONCLUS, Pamela; PUJOL TARRÉS, Joan. Propuestas para una difracción crítica del trabajo etnográfico. En http://psicologiasocial.uab.es/fic/ca/node/118 (19-05-2011).

(1995) HARAWAY, Donna J. Ciencia, cyborgs y mujeres: la reinvención de la naturaleza. Madrid: Cátedra.

(1999) JOCILES RUBIO, María Isabel. "Las técnicas de investigación en antropología", en Gazeta de Antropología, 15.

(2006) LAGUNAS, David. "Crítica cultural desde la perspectiva local: una etnografía Otomí", en Regiones, 16: 151-159.

(2006) KOTTAK, Conrad Phillip. Introducción a la antropología cultural. Un espejo para la humanidad. Madrid: McGraw-Hill, 20.

(1990) LLOBERA, Joan R. La identidad de la antropología. Barcelona: Anagrama.

(1986) MARCUS, George; FISCHER, Michael. La antropología como crítica cultural. Buenos Aires: Amorrortu.

(2006) MARZANO, Marco. Etnografia e ricerca sociale. Bari: Laterza.

(2002) PIASERE, Leonardo. L'etnografo imperfetto. Esperienza e cognizione in antropologia. Bari: Laterza.

(1992) RABINOW, Paul. Reflexiones sobre un trabajo de campo en Marruecos. Madrid: Júcar.

(1997) RAPPORT, Nigel. "Edifying anthropology. Culture as conversation; representation as conversation", en JAMES, Allison; HOCKEY, Jenny; DAWSON, Andrew (Edits.). After Writing Culture. Epistemology and Praxis in Contemporary Anthropology: 177-193 Londres: Routledge.

(1997) REED-DANAHAY, Deborah. Auto/Ethnography. Rewriting the Self and the Social. Oxford: Berg.

(2003) SEVILLA CASAS, Elías; et allí. El espejo roto: ensayos antropológicos sobre los amores y la condición femenina en la ciudad de Cali. Cali: Universidad del Valle.

(2003) STREET, Susan. "Representación y reflexividad en la (auto)etnografía crítica; ¿voces o diálogos?", en Nómadas, 18: 72-79.

(1988)VAN MAANEN, John. Tales of the Field: On Writing Ethnography. Chicago: The University of Chicago Press. 